Erratum

\title{
Erratum to "Overhydroxylation of Lysine of Collagen Increases Uterine Fibroids Proliferation: Roles of Lysyl Hydroxylases, Lysyl Oxidases, and Matrix Metalloproteinases"
}

\author{
Marwa Kamel, ${ }^{1}$ Mohamed Wagih, ${ }^{2}$ Gokhan S. Kilic $\mathbb{D}^{3},{ }^{3}$ Concepcion R. Diaz-Arrastia, \\ Mohamed A. Baraka, ${ }^{5,6}$ and Salama A. Salama $\oplus^{7}$ \\ ${ }^{1}$ Department of Tumor Biology, Unit of Pharmacology, National Cancer Institute, Cairo University, Giza, Egypt \\ ${ }^{2}$ Department of Pathology, Faculty of Medicine, University of Beni-Suef, Beni-Suef, Egypt \\ ${ }^{3}$ Department of Obstetrics \& Gynecology, University of Texas Medical Branch, Galveston, Tx, Usa \\ ${ }^{4}$ Department of Obstetrics, Gynecology and Reproductive Sciences, Mcgovern Medical School, Houston, Tx, Usa \\ ${ }^{5}$ Department of Clinical Pharmacy, Faculty of Pharmacy, Al-Azhar University, Cairo, Egypt \\ ${ }^{6}$ Department of Pharmacy Practice, College of Clinical Pharmacy, University of Dammam, Dammam, Saudi Arabia \\ ${ }^{7}$ Department of Pharmacology \& Toxicology, Al-Azhar University, Cairo, Egypt
}

Correspondence should be addressed to Salama A. Salama; salamas@hotmail.com

Received 8 May 2018; Accepted 27 May 2018; Published 18 July 2018

Copyright (C) 2018 Marwa Kamel et al. This is an open access article distributed under the Creative Commons Attribution License, which permits unrestricted use, distribution, and reproduction in any medium, provided the original work is properly cited.

In the article titled "Overhydroxylation of Lysine of Collagen Increases Uterine Fibroids Proliferation: Roles of Lysyl Hydroxylases, Lysyl Oxidases, and Matrix Metalloproteinases" [1], there was an error in the affiliation of the second author. The corrected affiliations are shown above.

\section{References}

[1] M. Kamel, M. Wagih, G. S. Kilic, C. R. Diaz-Arrastia, M. A. Baraka, and S. A. Salama, "Overhydroxylation of lysine of collagen increases uterine fibroids proliferation: roles of lysyl hydroxylases, lysyl oxidases, and matrix metalloproteinases," BioMed Research International, vol. 2017, Article ID 5316845, 13 pages, 2017. 


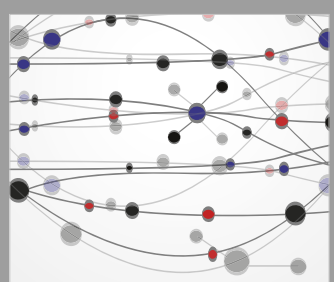

The Scientific World Journal
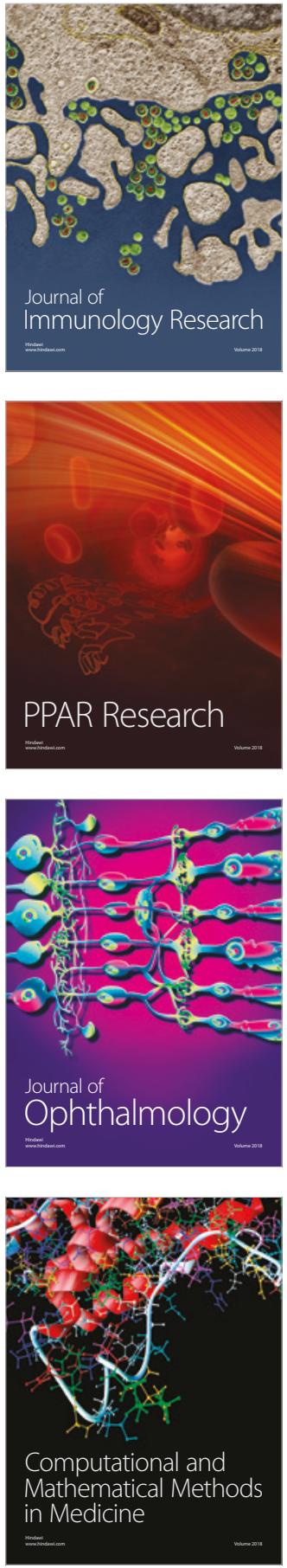

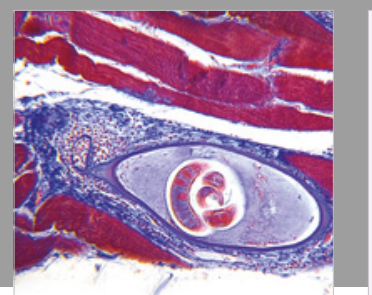

Gastroenterology Research and Practice

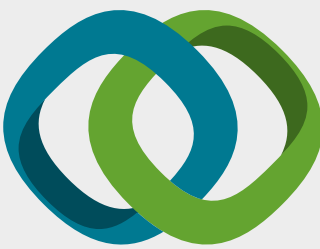

\section{Hindawi}

Submit your manuscripts at

www.hindawi.com
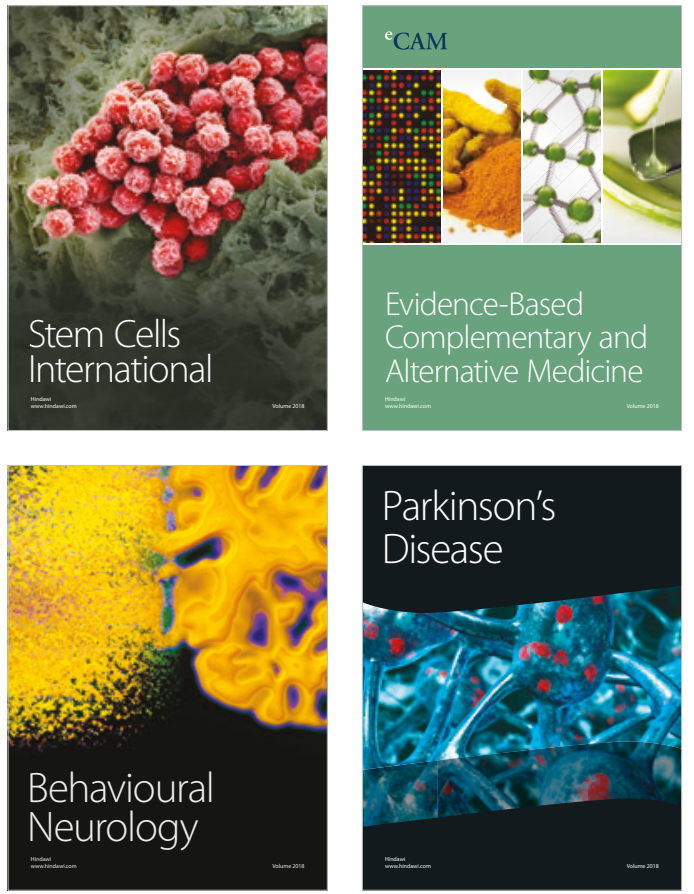

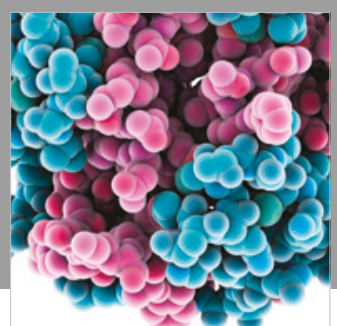

ournal of

Diabetes Research

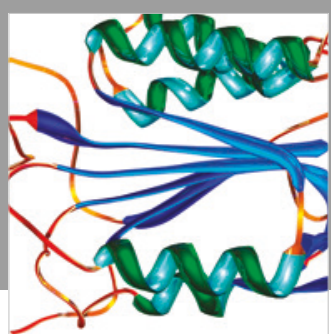

Disease Markers
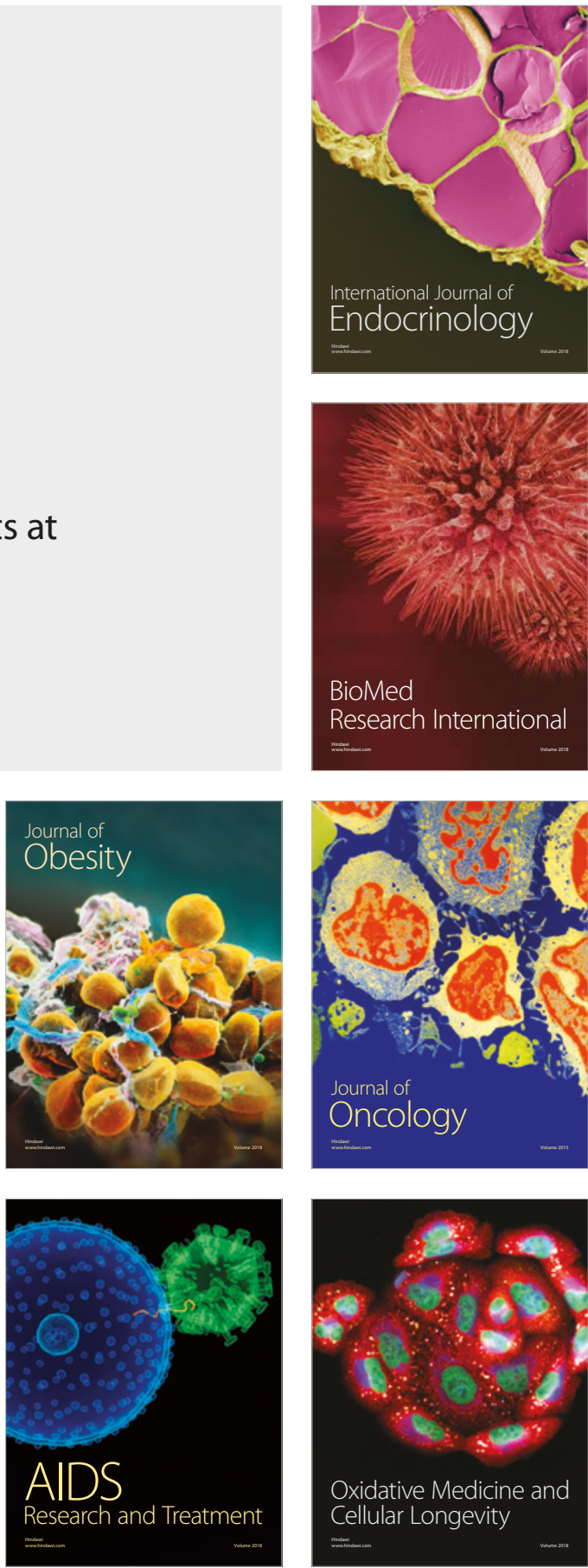